\title{
The impact of psychological factor on the aircraft operation safety
}

\author{
Tetiana Tarnavska ${ }^{1}$, Lilia Baranovska $^{1}$, Natalia Glushanytsia ${ }^{1}$, and Serhii Yahodzinskyi ${ }^{2, *}$ \\ ${ }^{1}$ National Aviation University, Liubomira Guzara av., 03058, Kyiv, Ukraine \\ ${ }^{2}$ International European University, Vernadskogo av., 02000, Ukraine
}

\begin{abstract}
Awareness of the radio exchange problems and the robust skills of recognizing and eliminating errors in radio communication will help to free up time and attention for the pilot and air traffic controller (ATC) to efficiently carry out their main professional functions in any circumstances. It is vitally important for pilots and ATCs in stressful situations not to focus their attention on the foreign language interaction that is the activity that only accompanies their main job performance. Analysis of aircraft accident investigation reports shows that languagerelated accidents mostly have psychological nature. The authors suggest a range of mental and psychophysiological qualities that determine professional competence and reliability of pilots and ATC. They also identify the sources of neuropsychic stress in critical situation and the ways to overcome it. The research results enable to design a language training model based on the analysis of the last-minute records and aircraft accident and incident reports to be able to identify typical problems of radio exchange, fatal language errors which led or could lead to a disaster. The research is aimed at improving aircraft operation and eventually increasing flight safety.
\end{abstract}

\section{Introduction}

The continuous improvement of aviation technology creates the background for a higher level of flight safety. However, the decrease in the number of accidents and incidents due to technical malfunctions is accompanied by increasing human errors as a contributing factor to accident causation.

According to the International Civil Aviation Organization Accident Statistics [1], more than $80 \%$ of all aircraft accidents are caused by human factor. In case of language-related accidents, the main cause is the human factor's psychological aspect [2].

With the growth of aircraft passenger-carrying capacity the human cost of disasters is increasing. In three largest accidents in the history of aviation, more than 800 people lost their lives [3]. The cases were called "language accidents" when the wrong use of language resulted in the tragedies.

\footnotetext{
* Corresponding author: yahodzinskyi.serhii@gmail.com
} 
Lindhout's and Ale's [4] study demonstrates that language issue related risks are often underestimated despite ICAO pays enough attention to pilot's and ATC's language proficiency.

One of the causes of poor communication is obviously the lack of proper language training for pilots and air traffic controllers (ATC). At the same time, inability to maintain radio communication in emergency situations, when standard phraseology is inapplicable [5], is often a psychological problem which must be taken into account while teaching English as a second language.

Aviation accident analysis shows that the leading cause for the air disasters is not just the low level of pilots' and air traffic controllers' English proficiency, but the inability to apply their knowledge and skills in emotionally stressful situations. Bor, Eriksen, Oakes and Scragg [6] describe a range of psychological issues and problems that may affect pilots and the consequences of these. Truschzinski, Betella, Brunnett and Verschure [7] investigate how the difficulty of complex tasks, which require attention and high precision, influences emotional states, cognitive workload and task performance. To solve these problems, Cushing [8] studies dozens examples of ambiguities in language and proposed a visual communication system and a computerized voice mechanism to help clear up confusing language. We in turn are looking for the ways to remedy the additional tension caused by the necessity to communicate in a foreign language by changing approaches to train pilots and ACTs.

The task of language training is the error-free transmission of messages and their correct interpretation without misunderstanding. "Ambiguous, misleading, inappropriate or poorly constructed communication, combined with expectancy are considered to be elements of many accidents" [9] as well as the psychological unpreparedness to use a foreign language in a non-standard situation.

The language barrier and its direct interference in aviation accidents with fatality became the issue for discussion after the mid-air collision of IL76 aircraft (Kazakhstan) and Boeing 747 (Saudi airline) over India in 1996, which resulted in deaths of 349 people. Special attention was paid to the problem of pilot's and ATC's interaction reliability in extreme situations.

The Proficiency Requirements in Common English Study Group (PRICESG) studied the issues of reliable radio exchange on the international airlines; and ICAO's Secretary General approved the first edition of the Doc 9835 - Manual on the Implementation of ICAO Language Proficiency Requirements - based on their research in September 2004.

The critical role of English in aviation is now being permanently studied. Friginal, Mathews and Roberts [10] provide introduction to turning research on Aviation English into practice, and recommendations how to teach successful intercultural communication. Trippe and Baese-Berk's [11] as well as Wu, Molesworth and Estival's [12] studies show how miscommunication may create difficulties for pilots and ATCs.

Despite of big attention which is currently paid to this problem, it still remains unresolved. Statistics about causes of Fatal Accidents [13, 14] doesn't categorize the language factor. Therefore, we devoted our research to the pilots and ATCs ability to cope with tension under stress while conducting the radio exchange in the non-native language.

Having studied the ICAO documents, accident reports and scientific publications on the issue, we defined the typical problems of radio exchange:

- erroneous interpretation of transmitted messages (e.g., due to the expectation of another message);

- inefficient aviation language communication in radio exchange between non-English speaking pilots and air traffic controllers, and therefore the simultaneous use of their native languages, which leads to a phenomenon called "code switching"; 
- improper use of the language because of the emotional level of communication;

- difficulties caused by the transmission medium;

- transmission of ambiguous messages;

- physical difficulties in listening or speaking caused by e.g. stuffiness in ear;

- errors related to the particularities of English;

- the numbers transposition, i.e. reproduction them in the wrong order;

- pronunciation and intonation related errors;

- feedback errors, when the pilot confirms the ATC's instructions incorrectly, and the ATC does not notice it, and doubtful information is not specified;

- errors of auditory perception;

- violations of the standard phraseology of radio exchange.

The aim of this study is to analyze the fatal language errors and typical problems of radio exchange, in order to identify the sources of neuropsychic stress of pilots and air traffic controllers and the ways to overcome it in extreme situations.

\section{Background}

It is timely to refer here to the review the largest disaster in aviation history at the airport on the island of Tenerife on March 27, 1977.

\section{Los Rodeos airport, Tenerife}

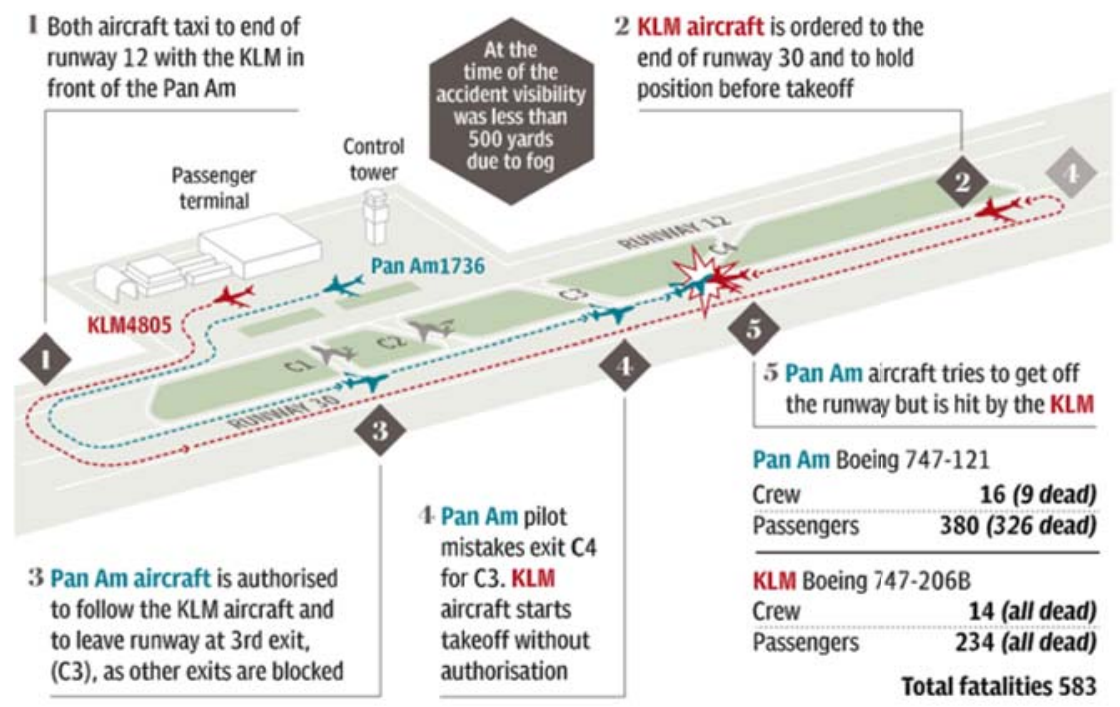

Fig. 1. Tenerife aircraft disaster information.

The Dutch pilot of the KLM airline, who wanted to send a message that they were starting to take off, made a mistake that became fatal for 583 passengers and crew members of two Boeing 747 aircrafts. Investigating the records of the last minutes of the radio exchange, even language specialists could not immediately recognize the error. Instead of the standard phraseology of the radio exchange "we are taking off» (i.e, we have not yet taken off, but we have already begun to run along the runway) the pilot used the construction of his native language «we are now at take-off (non-standard phrase which, for English speakers, sounds as «we are now at the line up position» because the preposition 
"at" in Dutch means the same as Continuous in English). The Dutch pilot unintentionally used the construction of his native language, which was defined by the Doctor of Philology Steven Cushing [8] as "Code Switching".

The Spanish ATC accepted the message as information about the location of the aircraft waiting for his permission to start taking-off didn't beat an alarm that another Boeing 747 had not yet vacated the runway.

This example indicates not just a violation of the standard phraseology of radio exchange, but, most importantly, the lack of ability to reliably apply knowledge in practice.

The reasons for switching the code have not yet been sufficiently studied, but it is reasonable to assume that this phenomenon can occur much more often in extreme situations. The misunderstanding and misinterpretation that it can cause is very difficult, sometimes unrealistic, to predict. Neither knowledge of the English language, nor knowledge of standard phraseology guarantees the reliability of radio exchange in nonstandard situations without the ability to analyze each received message and the robust skills for recognizing errors and clarifying ambiguous information.

Another accident happened at John Wayne Orange County Airport (Santa Ana, CA) on 17th February, 1981. The Air Cal 336 received landing permission, while another Air Cal 931 received permission to take off. However, the ATC decides to delay the landing of Air Cal 336 and instructs him to execute a go-around. For some reason, the captain of the Air Cal 336 ignores this indication and continues to ask for permission to land. "When the controller cleared 931 into position, he did not tell him to expedite. He merely stated, "Taxi into position and hold." (Emphasis added.) "Be ready." Nor did the controller, when 931 was cleared for takeoff while still 90 degrees from runway lending, tell him to expedite takeoff." Using the word "hold", the ATC inadvertently switched from technical aviation jargon to plain English.

In aviation English, "hold" always means stopping doing what we are doing now. In this case, this meant that the pilot would continue go around rather than landing. But in colloquial language, "hold" can also mean a continuation of what we are doing (in this case, landing). The similarity of the call signs of both aircraft and the apparently contradictory instructions of the controller "go ahead" ("continue") and "hold" ("wait") exacerbated the situation. When the pilot decided to go around, it was too late. Air Cal 336 landed with retracted landing gear. As a result of the incident 34 people were injured.

While words with multiple meanings give English a linguistic richness, however, this accident shows that they can also create ambiguity, which easily leads to misunderstanding like in the following example.

On March 5, 1973, a Boeing 747-249F of the Flying Tiger Line airline received permission to drop to an altitude of 2,400 ("... descend two four zero zero ...") when landing at Kuala Lumpur-Subang (KUL). However, the numeral "two" and the preposition "to" sound exactly the same in English, and the pilot understood the ATC's instruction as "lowering to a height of 400 " ("... to four zero zero ..."). The aircraft crashed into a hill.

This example illustrates a large number of words with the same pronunciation, but with different meanings in English and confirms the need to familiarize student ATCs with the tragic experience of their misuse in order to form the ability to avoid such communication errors.

Miami International Airport (Florida), December 29, 1972. The pilot and crew of Eastern Airlines were preoccupied with the front landing gear problem (which they reported to the controllers along the route) when the Miami International airport ATC discovered the height loss, and asked "How are you doing?". The pilot's reply was "Good" as the crew was focused on the problem with the landing gear, which they finally managed to cope with, and had no idea that they had any problems with the altitude. The ATC 
accepted their answer as everything was all right with the height because he had asked exactly about that. 101 people were killed [8].

On January 25, 1990, at the Cove Neck NY airport, one of the reasons for the accident was the use of the colloquial phrase "running out of fuel" instead of the aviation term "emergency", most accurately characterizing that situation. The ATC didn't understand the degree of urgency of the measures.

These examples illustrate the inadmissibility of the use of ambiguous phrases, as they might be a source of misunderstanding and have repeatedly caused aviation accidents and incidents.

One of the problems of radio communication "aircraft pilot - ATC" is the feedback error (pilot error when repeating a message received from the controller). This is especially true for digital indicators. At the same time, the ATC does not notice the pilot's error because people often hear what they hope to hear.

Having studied the reports of pilots and controllers, aviation experts came to the conclusion that there are four main sources of this problem:

1) the similarity of aircraft call signs;

2) only one pilot conducts radio communication at the air traffic control frequency, while the second pilot is engaged in negotiations with the automatic terminal information service (ATIS) or with the airline;

3) discrepancies between what is "on the mind" and what is "on the tongue", e.g.:

- receiving a message about the flight at another flight level and interpreting the information as the permission to occupy that flight level;

- confusion with "10000" and "11000" when indicating the flight level;

- confusion with "Right"/“Left" with parallel runways;

- understanding the airspeed limitation "keep ... (speed)" as the flight altitude;

4) programmed thinking and expectation factor: when receiving an unclear or unreadable signal, a pilot who requests information tends to hear what he expects to hear [3].

Awareness of the radio exchange problems and the robust skills of recognizing and eliminating errors in radio communication will help to free up time and attention for the pilot and ATC to carry out their main professional functions in any circumstances. It is vitally important when they face an emergency as they don't need to focus their attention on the foreign language communication.

When air traffic is heavy, ATCs do not pay much attention on if pilots repeat their messages correctly. Sometimes controllers do not confirm the feedback and pilots, in turn, accept ATCs' silence as the confirmation.

Another problem is that controllers do not ask for confirmation of unclear messages (those that they have poorly or not fully heard). We consider that discipline; wide breadth and long-term span of attention, ability to concentrate, distribute and switch attention easily; integral, selective and accurate perception are to prevent mentioned above errors.

In accordance with paragraph 5.1.1.1 of Volume II of Annex 10 to the Convention on International Civil Aviation, "ICAO standardized phraseology shall be used in all situations for which it has been specified. Only when standardized phraseology cannot serve an intended transmission; plain language shall be used" [15].

Breaking this rule is allowed mainly in emergency situations when standard phraseology is inapplicable. As English is the international aviation language of radio exchange, it is often the only way to achieve mutual understanding between the pilot and ATC. ICAO Document 9835 exemplifies radio exchange record where plain language is used at $60 \%$. 
An insufficient level of proficiency in plain English can also lead to tragedy, as well as ignorance or violations of the standard phraseology of radio exchange. That is why the minimum working level of English proficiency on the ICAO scale requires "effective communication on general, specific and work-related topics". Tightening of ICAO requirements was the result of the growth of accidents and incidents due to the low level of non-English speaking pilots' and ATCs' English proficiency.

However, aviation accidents indicate that even certificated pilots and controllers who speak English at a fairly high level to fly at the international air routes are not able to effectively apply their knowledge, skills and abilities in non-standard situations, to recognize and eliminate radio exchange errors and to successfully complete their task.

Aviation English itself does not solve the problem. The term "aviation English" often implies only knowledge of aviation terminology, which is unacceptable when training operators of complex control systems. Peculiarities of the professional activities of pilots and air traffic controllers require a different approach to their training. Aviation English is used in any non-standard radio exchange to conduct error-free (not allowing misunderstanding) radio telephone communication.

Therefore, the ability to apply standard phraseology of radio exchange, aviation terminology and plain English in special situations, when the level of under neuroemotional stress and sharply limited time to make a decision are of vital importance.

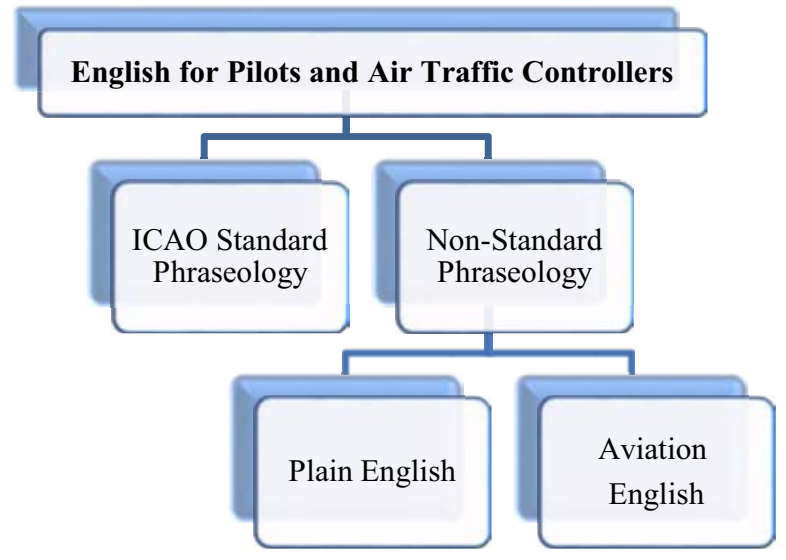

Fig. 2. English for Pilots and Air Traffic Controllers.

The expression "learn from your own mistakes" is unacceptable in civil aviation, where the passenger capacity of aircraft is growing steadily.

A striking example of the ATC's inability control his emotions and to use the foreign language in extreme situation, was the accident in the sky over Zagreb on September 10, 1976. A few seconds before the collision, when the controller of Zagreb Airport ATC Center realized the inevitability of a collision, yelled "Adria, immediately stop climbing and report to Zagreb!", but he did it in his native Croatian language. The Douglas-9 InexAdria Aviapromet aircraft pilot with 108 passengers on board had no idea that they were on a collision course with the British Airline Trident 3B G-AWZT aircraft with 54 passengers on board. He asked for clarification: "At what height should we stay?" However, the ATC continued hysterically shouting commands in Croatian: "Adria, the plane is approaching you on your left! Do not dare to climb! Report the passage of Zagreb!" The tone in which this was said probably convinced the aircraft captain of the emergency situation, but he did not manage to take any action to change the course or altitude. 
Awareness of the need to speak a non-native language in an extreme situation causes a decrease in motivation to complete the complex task, further increases the already high level of psycho-emotional stress, suppresses determination and willpower, reduces quality of memory and attention. It consequently prevents the successful implementation of the main professional activity.

Thus, flight safety is determined by the ability to accurately control air traffic in extreme situations and directly depends on the reliability of radio communication between the ATC and the aircraft pilots.

\section{Methods}

Data analysis and archival study of the fatal mistakes was the key method in this research. Studying aircraft accident investigation reports made it possible to identify not only typical communication errors, but also completely unexpected ones, to understand their psychological nature.

\section{Results}

Having analysed the large number of aircraft accidents [8, 16, 17], we identified the mental and psychophysiological qualities that determine the professional competence and reliability of pilots and air traffic controllers in extreme situations. They are:

- practical and professional intelligence;

- practical thinking;

- logical thinking, the ability to analyse, the ability to search for regularities, developed analytical and synthetic side of intelligence;

- efficiency and practicality of thinking, i.e. the ability to make quick and correct decisions in a complex and frequently changing environment;

- the ability to perform various types of mental actions at a high pace;

- highly developed operational, short-term and long-term memory;

- high noise immunity and ability to work in the limited time available;

- developed capacity of attention and the ability to concentrate, fix, distribute and shift it;

- accuracy and constancy of perception;

- the ability to assess the duration of actions;

- high mobility, lability and strength of nervous processes;

- good characteristics of psychomotor reactions (such as psychomotor pace, hand-eye coordination, etc.);

- developed imagination and constructive thinking;

- moderate radicalism of thinking, the ability to make non-standard decisions, think outside the box;

- purposefulness;

- integrity and selectivity of perception and attention;

- tolerance to frustration - psychoemotional stability in situations characterized by the presence of obstacles to achieving the goal;

- a low level of emotional sensitivity, vulnerability, gentleness, empathy;

- the ability to sufficiently activate mental processes and achieve the optimal level of excitation of the higher parts of the central nervous system;

- developed visual-effective and heuristic thinking; 
- an adequate level of claims;

- low neuroticism, stability of the emotional sphere;

- the ability for optimal behaviour in conflict and frustrating situations;

- low aggressiveness and ability not to put the blame on others;

- easy and fast development of new skills and their modernization;

- low motivational stress;

- adequate self-esteem.

The peculiarity of the professional activity of a pilot and ATC is emotional excitement and emotional stress. Emotional arousal leads to the mobilization of functional reserves and an increase in the effectiveness of professional activity only up to a certain critical value. Its further increase leads to a decrease in the quality of attention and memory, impairing of motor coordination and reaction time, a decrease in the criticality of thinking and, as a result, fatal errors.

The need to conduct radio communications in a non-native language significantly increases emotional stress, unless stable knowledge, skills and abilities, high Englishspeaking competence to provide reliable radio communications in extreme conditions of activity are formed.

Considering that shifts in the human body depend not only on the strength of the influencing psychogenic factors, but also on the degree of adaptation to them, the language training of student pilots and ATCs at the international air routes should be organized in such a way that its educational impact is aimed at the formation of a highly organized, a flexible-coordinated adaptation complex in accordance with the purpose of their professional training.

When developing a methodology for training student pilots and ATCs in extreme situations on the international air routes, we used the results of scientific research, in which the factors causing the tension of the state of the operator of especially complex control systems and the ways to overcome it were identified, as well as the sources of neuropsychic stress due to the objective and subjective characteristics of their professional activities:

These studies make it possible to determine the following ways to overcome neuropsychic stress in extreme situations and use them for pilots and ATCs training:

- studying of the aircraft accident investigation reports systematically and consistently [18];

- modelling conditions for critical situations involving radio exchange in the international aviation language of radiotelephone communication;

- accumulating of experience in solving conflict situations while having to conduct radio exchange in the non-native language;

- gaining experience in solving problems with highly intensive and frequently changing flow of incoming information in English;

- gaining experience in requesting missing data in English;

- training of the ability to conduct radio exchange in English under radio frequency interference to air traffic control communications;

- developing ability to recognize different national accents and dialects by listening to the recordings of a real radio exchange "ATC controller - aircraft crew";

- accumulating experience in decision-making while simultaneously

- getting information from several sources and its preliminary ranking;

- developing skills to recreate models of dynamic air situations and ATC action courses when a large flow of information is received in a non-native language and there is no visual contact; 
- developing skills and abilities to conduct radio communication in English under time shortage by limiting the time to complete the task;

- developing skills to transmit messages clearly, unambiguously and appropriately to provide well-constructed and error-free communication in English;

- developing long-term and operational memory;

- developing attention skills.

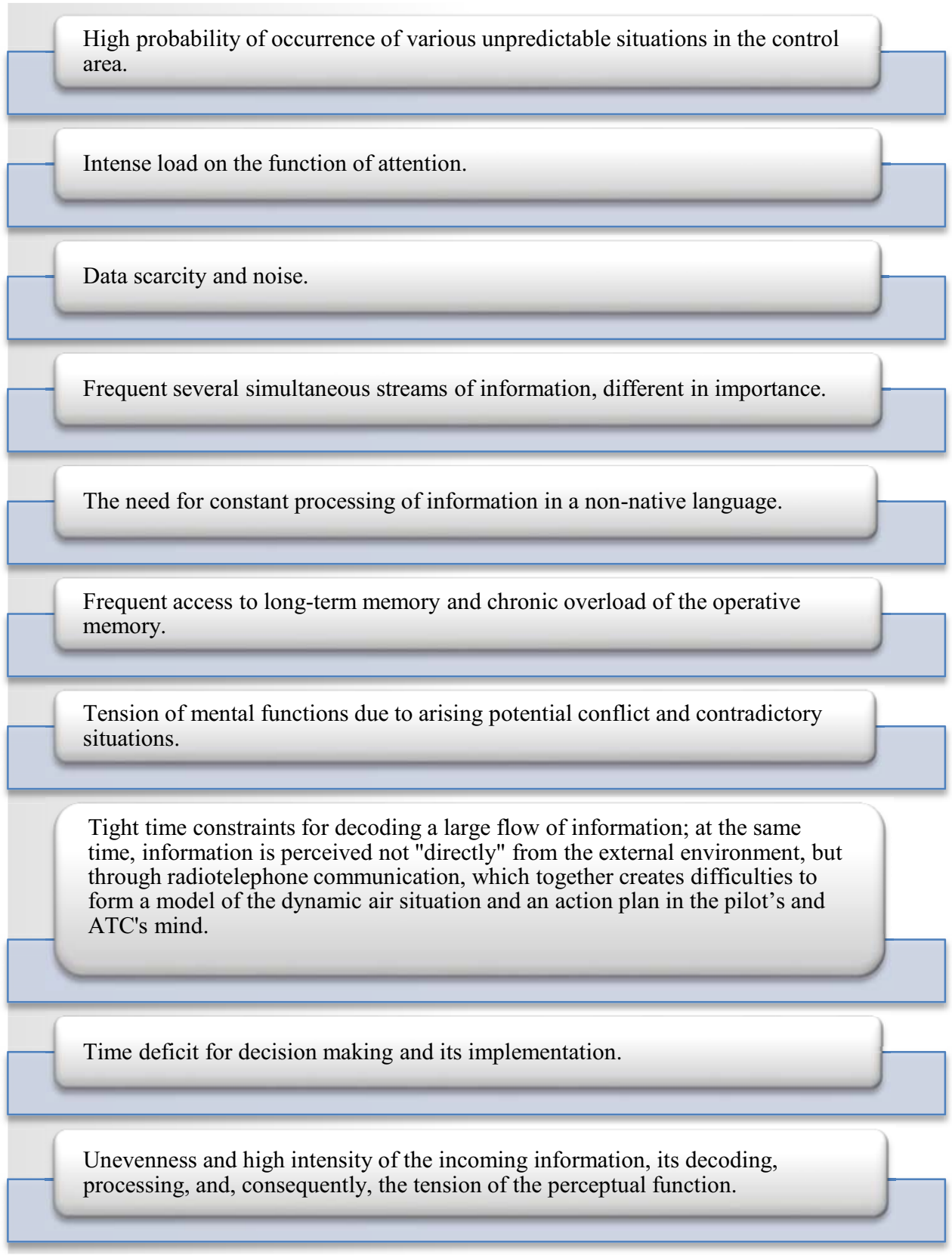

Fig. 3. Sources of neuropsychic stress. 


\section{Conclusion}

Knowing the mental and psychophysiological qualities that determine professional competence and reliability of pilots and air traffic controllers and the sources of neuropsychic stress in extreme situations, makes it possible to design language training model in such a way as to develop the ability to conduct reliable radio communications in the non-native language in emergency situations. The further research will be devoted to the development of Aviation English training system taking into account the human factor psychological aspect.

\section{References}

1. ICAO Accident Statistics International Civil Aviation Organization, https://www.icao.int/safety/iStars/Pages/Accident-Statistics.aspx

2. G. Matthews, C. Neubauer, J. Saxby, W. Wohleber, J. Lin, Accident Analysis \& Prevention 126, 85-94 (2018) https://doi.org/10.1016/j.aap.2018.04.004

3. Doc 9835-AN/453. Manual on the Implementation of the ICAO Language Proficiency Requirements (2004)

4. P. Lindhout, J. Kingston, G. Reniers, Process Safety and Environmental Protection (2019) https://doi.org/10.1016/j.psep.2019.06.017

5. S. Gilmour, Aviation English (London and New York, 2017) https://doi.org/10.1016/j.esp.2017.05.003

6. R. Bor Eriksen, M. Oakes, P. Scragg, Pilot mental health assessment and support: A practitioner's guide (Oxon Routledge, 2017)

7. M. Truschzinski, A. Betella, G. Brunnett, P. Verschure, Applied ergonomics 69, 1-9 (2017) https://doi.org/10.1016/j.apergo.2017.12.019

8. S. Cushing, Fatal Words: Communication Clashes and Aircraft Crashes, 1997.

9. Human Factors Training Manual Doc. 9683 (International Civil Aviation Organization, Montreal Canada)

10. E. Friginal, E. Mathews, J. Roberts, English in global aviation: context, research, and pedagogy (Bloomsbury, London and New York, 2019) https://doi.org/10.1080/01434632.2020.1805158

11. J. Trippe, M. Baese-Berk, A prosodic profile of American Aviation English. English for Specific Purposes 53, 30-46 (2018) https://doi.org/10.1016/j.esp.2018.08.006

12. Q. Wu, B. Molesworth, D. Estival, The International Journal of Aerospace Psychology (2019) https://doi.org/10.1080/24721840.2019.1604138

13. Accident Statistics, http://www.planecrashinfo.com/cause.htm

14. E. Mathews, A. Brickhouse, Ph. Carson, E. Valdes, Accidents and Serious Incidents: A Handbook for Accident Investigators (2019)

15. Aeronautical Telecommunications. Vol II. Communication Procedures including those with PANS status Seventh Edition (2016)

16. A. Garcia, Journal of pragmatics $\mathbf{1 0 6}, \quad 57-71 \quad$ (2016) https://doi.org/10.1016/j.pragma.2016.10.005

17. Jr. Benner, Safety $\quad$ science 118, 309-315 https://doi.org/10.1016/j.ssci.2019.05.021

18. T. Tarnavska, N. Glushanytsia, Journal of Kirsehir Ahi Evran University 3(2), 129-142 (2019) 